\title{
Brain Metastatic Disease in a Patient with Tall Cell Thyroid Carcinoma
}

Ioannis Georgiadis, Ifigenia Kostoglou-Athanassiou

Endocrinologist, Chios, Greece

Department of Endocrinology, Red Cross Hospital, Athens, Greece 


\section{Introduction}

- Papillary thyroid carcinoma is a disease associated with a very good prognosis

- However, there are some subtypes of papillary thyroid cancer which are associated with aggressive biological behavior and worse outcome

- The appearance of brain metastatic disease in the course of papillary thyroid carcinoma is rare and carries an unfavorable prognosis 


\section{Aim}

- The aim was to describe the case of a patient with tall cell papillary thyroid carcinoma who presented with brain metastatic disease 


\section{Methods}

- A patient, male, aged 63 years, presented with a large mass in the area of the thyroid causing dysphagia

- Initial evaluation with thyroid hormone measurement and a fine needle aspiration biopsy revealed the presence of malignancy

- Near total thyroidectomy was performed 


\section{Results}

- On histology a large tumor measuring $7.0 \times 7.0 \times 5.0 \mathrm{~cm}$ and weighing $122 \mathrm{~g}$ was examined

- The tumor was multilobular, scleroelastic and had a small area of fibrosis and an area of cystic degeneration

- The neoplasm was a tall cell papillary thyroid carcinoma which had foci of dedifferentiation

- Within the area of low differentiation atypical mitoses were observed with a Ki67 index of approximately $10 \%$

- The tumor was positive to p53 in 50\% of the cells

- Extrathyroidal extension was observed

- After near total thyroidectomy therapeutic radiodine was administered

- Approximately a year later the patient presented with brain metastases 


\section{Conclusions}

- Brain metastatic disease from thyroid cancer is rare and carries a bad prognosis

- Some subtypes of papillary thyroid cancer, such as the tall cell variant have an increased propensity to develop metastatic disease, including brain metastatic disease

- In conclusion, the case of a patient with a tall cell thyroid carcinoma with areas of low differentiation is presented who developed early brain metastatic disease 


\section{References}

- Tahmasebi FC, Farmer P, Powell SZ, Aldape KD, Fuller GN, Patel S, Hollis P, Chalif D, Eisenberg MB, Li JY. Brain metastases from papillary thyroid carcinomas. Virchows Arch 2013;462:473-80 